\title{
A UCRANEIDADE EM POESIA: história e literatura na arte de escrever
} Paulo Augusto Tamanini

\section{RESUMO}

Helena Kolody é conhecida pelos ucranianos e descendentes, moradores de Curitba- PR, como a poetisa que soube com maestria materializar pela arte da escrita os sentimentos de pertencimento e identificação étnico-religiosa. Este artigo propõe refletir o poema como expressão literária da arte que traduz e expõe sensibilidades étnico-culturais da autora que se baseou na memória, nos acontecimentos e nas percepções religiosas para construir versos sobre a sua ucraneidade. Para tanto, tendo como referencial teórico de Eni Orlandi e servindo-me dos pressupostos e metodologia que cercam a História Cultural busco enxergar na poesia de Helena Kolody não apenas uma obra literária, mas um discurso repleto de fontes e pistas que aproximam o pesquisador de um pretérito repleto de subjetividade e que expressam os contornos de um mundo reconfigurado por valores, desejos e esperanças que trazem tonalidades e acentos próprios.

Palavras-chave: Literatura e historiografia, poesia e documento, Helena Kolody

\section{THE UCRANEIDAD IN POETRY: history and literature in the art of writing}

\begin{abstract}
Helena Kolody is known by the Ukrainians and their descendants, residents Curitba-PR as a poet who knew how to skillfully materialize, the art of writing, the feelings of belonging and ethno-religious identification. This article aims to reflect the poem as literary expression of art that reflects and exposes the ethnic and cultural sensitivities of the author which was based on memory, and perceptions of events to build on its verses Ukraine. For both, the theoretical reference of Eni Orlandi and serve me the methodology and assumptions surrounding the Cultural History seek to see the poetry of Helen Kolody not only a literary but a speech full of sources and clues that bring the researcher a past tense and fraught with subjectivity that express the contours of a world reconfigured by values, hopes and desires that bring own hues and accents.
\end{abstract}

Keywords: Literature and Hitoriografia - Poetry and source - Helena Kolody. 


\section{Os olhos que se cruzam: História e Literatura}

Não cabe aqui discutir a influência da Literatura como fonte de inspiração narrativa para muitos pesquisadores do século XIX que discorreram sobre o pretérito. Até porque no final do mesmo século, o cientificismo descredenciava a narrativa literária de se fazer história e tentava substituí-la por uma narrativa ancorada nas comprovações de fontes documentais afastando-se o quanto possível da ficção. A Escola dos Annales fundada na França no século $\mathrm{XX}$, por sua vez, redescobriu na Literatura fonte para a historiografia, dando-lhe um novo sentido e um novo lugar epistemológico, tão cara à história das mentalidades e à microhistória (SILVA, 2001).

Passados algumas décadas, a discussão sobre o uso de escritos literários na feitura de narrativas historiográficas ressurgiu baseada e tendo como pressuposto que a literatura e a história eram discursos e, como tais, estavam sujeitos à influência das subjetividades. Se os documentos não apareceram do nada, por serem limitados às condições de tempo, espaço e cultura, para os historiadores, cientes de que nem sempre os documentos podem ser abalizados como provas incontestáveis do acontecido, tornou-se imperioso a prática da defrontação com outras fontes e de naturezas diversas. Desta feita, no regime moderno da historiografia, todo e qualquer documento utilizado como fonte deve ser prudentemente relativizado e confrontado, já que também ele, em sua gênese ou elaboração está sujeito aos mais diversos fatores externos.

Se a História foi por muito tempo acusada por relatar o passado pela óptica dos vencedores, a Literatura por sua vez de igual modo era apontada por privilegiar, movidas por interesses das classes dominantes, os autores consagrados em detrimento daqueles que se escondiam no anonimato. Para além dos limites e das deficiências de cada área do conhecimento, Literatura e História, no novo regime da historiografia, se cruzam e buscam, utilizando-se de suas especificidades, complementar e enriquecer narrativas. Na esteira desse pensamento, a historiadora Sandra Jatahy Pesavento (2005, p. 82) alerta que "a Literatura permite o acesso à sintonia fina ou ao clima da época e ao modo pelo qual as pessoas pensavam o mundo, a si próprias, aos valores que guiavam seus passos, quais os preconceitos, medos e sonhos".

As diferenças não servem mais de pretextos e motivos de acusação ou de invalidação do caráter científico, e agora tidos por substratos que enriquecem os relatos. Se o olhar do 
historiador nem sempre coincide com a maneira de um literato contemplar o passado, tal diferença não descredencia a forma, a metodologia e a maneira que um e outro se utilizam para expressar, representar e dizer suas verdades. Como sujeitos de um enunciado discursivo, tanto o historiador quanto o literato, se descortinam pelos condicionantes e contextos que os cercam. Se para Aristóteles (1986, p.115) "não é ofício do poeta narrar o que aconteceu, mas representá-lo", a História Cultural estende aos pesquisadores alguns cuidados, quando usa como fonte, por exemplo, a memória. Nestes casos a análise do relato leva em conta a arbitrariedade das palavras, já que sentimentos, esperanças e esquecimentos tendem a construir narrativas aportadas pelos registros parciais do acontecido.

Se o historiador tece a narrativa do acontecido atrelado aos métodos e às fontes que lhe garantem a credibilidade acadêmica, o poeta elucubra os dizeres (comprováveis ou não) alicerçado na capacidade de criar e recriar, buscando a unidade do pensamento daquilo que aconteceu ou daquilo que poderia ter acontecido. Assim, a poesia, tendo compromisso com certa linguagem literária, relê fatos, emoções e trajetórias sob a ótica de sua própria lógica, auxiliando o pesquisador a observar nas nervuras das emoções daquele escrito não só a frieza das fontes, mas o contexto e a subjetividade que em torno deles gravitam. Ainda que a narrativa histórica, influenciada pelas subjetividades, comporte omissões, acrescimentos e remanejamentos, estará alicerçada em fontes tangíveis, mensuráveis, integrando e estruturando o corpo do texto de tal maneira que sem elas o saber, que se quer científico, fica comprometido.

A poesia revela-se então como a antiga arte de escrever sobre o acontecido e sobre o que poderia ter acontecido embalado pelas mãos de quem tem os sentimentos substratos para conduzir um enredo. Sob a inspiração de poetas e historiadores, o passado é redesenhado pela destreza de quem tem a missão de fazer emergir das sombras do esquecimento, de maneira elegante e leve, não só o fato em si, mas muito de sua percepção. Caso a poesia então exponha fragmentos do passado utilizando-se de uma linguagem simbólica própria, o historiador à caça destes indícios, os seleciona e os observa não mais como elementos neutros, mas fortemente vinculados a construções culturais, logo, passíveis de interpretação. Se no dizer de Eni Orlandi (2009, p. 9), "toda leitura é objeto de interpretação" (e a poesia não é a exceção), o historiador ao se deparar com os versos está atento às sutilezas do estilo de quem os pensou e percebe que a emoção pode redirecionar o raciocínio por caminhos margeados por sentimentos e imagens do abstrato que é o seu real. A poesia e a história constroem reais 
específicos tendo como parâmetros modalidades de escrita conduzidas por uma lógica de estilo de linguagem ou de interpretação do simbólico inserido no acontecido. Haverá fácil interdisciplinaridade quando houver trânsito de dados e abertura por compreender que se tratam de duas naturezas da escrita cujo elemento textual pode ser lido e interpretado de acordo com os objetivos de cada campo discursivo. Utilizando-se da poesia, a narrativa histórica se reinventa ao descrever realidades não reveladas por documentos cartoriais, mas captadas por relatos sob forma de estrofes, rimas e combinações cuja comprovação pela verossimilhança escapa da sua feitura e preocupação primeira.

Assim, utilizando-me dos poemas de Helena Colody analiso o quanto de seus versos explicitam um discurso que revela seu vínculo com a cultura ucraniana herdada de seus pais. Seus versos não são observados apenas pelo viés da arte literária, mas como instrumento indiciário do acontecido que pode, além de explicar as expressões e os contornos subjetivos de sua obra, procurar compreender com mais largueza os sentidos e os significados que os fatos desencadearam em sua gente. Os versos da autora autodecifram sua latente ucraneidade.

\section{A poetisa e a cultura religiosa tecendo narrativas}

Em 1991, a poetisa de 79 anos, filha de pais ucranianos, paranaense e munícipe de Cruz Machado, Helena Colody passou a ocupar a cadeira n. 28 da Academia Paranaense de Letras, sob aplausos e reconhecimento de seus pares. A partir daquele dia o assento vinte e oito hospedava a ilustre paranaense, autora de versos que encantaram os olhos dos que tiveram a oportunidade de serem seduzidos pelo estupor de seus versos.

Helena Kolody desde mocinha lidou com a arte de escrever e ensinou os alunos de escolas públicas estaduais a se alfabetizar. O ofício do magistério sempre foi para ela a inusitada fonte de inspiração, levando-a a registrar em tinta sob versos e prosas as sutilezas do ordinário. Seus pais nasceram na Galícia Oriental, Ucrânia, o que explicava sua inclinação em escrever sobre a cultura e costumes de sua etnia; conhecida por ser a poetisa do cotidiano, das realidades simples e comuns, deixou refletir em seus poemas nesgas de saudades por sua descendência eslava-ucraína. Na esteira de seus versos, a história cata resquícios do acontecido para compreender sua ucraneidade.

Alguns versos de Helena Colody revelaram os fortes laços que nutria pela cultura herdada de seus pais. Por ouvir reiteradas vezes a narrativa da saída de seus parentes da 
Ucrânia e a sua posterior chegada ao Brasil, soube escrever com elegância sobre o sentimento da saudade: "tão longa a jornada! e a gente cai, de repente, no abismo do nada! Ao entrar na casa, pela porta que não existe, deparo-me com o que fomos" (COLODY, 1941, p.71).

Nestes versos, a nostalgia transportou a autora a um tempo vivido pelos outros, mas que fazia carne e sentimento em sua criação. A lembrança do que seus pais disseram sobre a travessia do Atlântico a inspirou em escrever sobre uma Ucrânia que não conheceu, mas que a imaginou e a eternizou sobre as linhas de folhas de papel. Imagens e sons apreendidos quando criança fizeram da menina sonhadora a grande senhora dos versos da nação ucraniana, digna do reconhecimento por parte da academia que lhe outorgou um lugar de distinção.

Se para Hobsbawn (1984, p. 19), o conceito de nação sofreu as influências do período e do contexto sociocultural onde foi formulado, a idéia de nação de muitos de descendência ucraniana revela que foi moldada por um estreito vinculo onde a língua, costumes e práticas religiosas se sobrepõem aos limites territoriais. Também Helena levou para a produção literária uma Ucrânia que impendia nas linhas de muitos poemas de sua antologia. A Ucrânia imaginada pela poetisa descobre-se pelos traços do alfabeto que dançavam ritmados sobre um impresso a espera de pensamentos que ali iriam permanecer e enraizar-se. A Ucrânia da poesia e do sonho ganhou território e lugar de legitimação na Literatura paranaense, antes mesmo de ser reconhecida como Nação em 1991, quando se desvencilhou de uma União Soviética já quebrantada.

Não só sentimentos pela pátria inspiraram a poetisa da cadeira 28 da Academia Paranaense de Letras. A cultura religiosa eslava também a marcou de maneira contundente: "os olhos da Mãe que segura o Menino, esbarraram em mim que seguro a saudade daquela fé que era minha”. Neste verso, a autora presentificou o ícone da Mãe de Deus que, segundo a religiosidade cristã oriental mostra a Virgem segurando Jesus Cristo nos braços. No ícone bizantino mãe e filho se olham. Poucas palavras qual retalhos colhidos construíram uma trajetória que trazia da memória uma identificação, um pertencimento religioso e a sensação de que sua crença era mais incisiva quando menina, e por isso a retrata com saudades! Poucas linhas abaixo, no mesmo poema, sugeriam que o impacto provocado pelos olhos que se esbarravam, acionavam mecanismos capazes de deflagrar recordações sobre uma fé adormecida que buscava e esquadrinhava aquela ânsia de ser e comunicar: "Olhos fitos no azul dos olhos daquela que me fez relembrar de como eu crera” (COLODY, 1941, p.13). 
Se o que interessava a autora era descrever o estupor que sentia ao fitar os olhos de Maria iconogrados em estilo bizantino, para o historiador tornou-se imperioso observar o caráter da experiência vivida por Helena que soube presentificar e eternizar sentidos por meio de versos, sem desenraizá-los do deslumbramento dos fatos. Diante dos vocábulos, tanto o poeta quanto o historiador remaneja as compreensões de mundo buscando uma síntese plausível entre um saber entranhado na vida da experiência, tratando de compreender e conciliar o pretérito em temporalidades, estilos e contextos distintos pelo viés da narrativa historiográfica ou literária.

No rastro deste pensamento, Eni Orlandi atentou para o fato de que ao se analisar as palavras de um escrito é preciso ter em mente que "a palavra discurso, etimologicamente, tem em si a idéia de curso, de percurso, de correr por, de movimento. O discurso é assim palavra em movimento, prática de linguagem" (ORLANDI, 2009, p.15). A trajetória de experiência de fé da poetisa seguiu afluentes que talvez a tenha distanciado da maneira como concebia a crença quando tinha pouca idade, mas que encontrou na lembrança ou na memória o curso de experimentar novamente aquela proximidade com as coisas sagradas. Helena, por vezes, não era direta em suas assertivas. Não poetizou que não mais cria, tão pouco afirmara que não tinha mais fé. O curso de suas palavras enfocou, no entanto, a nostalgia do tempo em que acreditar parecia tão natural e que encontrou em suas mãos modos subjetivos de sobre ela falar.

Mesmo que por trás das palavras da poetisa de descendência ucraniana se escondesse o explícito, tanto o fascínio do poeta quanto o prodígio de análise do historiador, arrancaram das entranhas do mistério um enunciado passível de ser compreendido e interpretado (ORLANDI, 2009, p. 26). Logo, o preciso, o claro e o formal, ainda que mascarados pelos tons, combinações e rimas dos textos, não escapam às análises do esmero. Por mais que pese a subjetividade na poesia da autora, estavam subjacentes informações que direcionavam para a identificação mística, herdada da cultura étnico religiosa dos pais e que o pesquisador não pode relegar. Observando estas estrofes sob esta óptica, é possível dizer que a literatura confere o postulado de se pensar os modos de ser pelo viés do imbricamento entre o comprovado e o provável.

A autora ao escrever sobre a saudade que a transferia para os idos da infância concedia à poesia a maneira de se falar do tempo para além de sua finitude, auxiliando o historiador a observá-lo como veiculador de sentidos que privilegiam a subjetividade. Assim, Helena 
discorreu versos sobre o quão fugidio lhe parecia o tempo e quão finita lhe parecia ser a vida: "Tudo o tempo leva. A própria vida não dura. Escorre-me das mãos os dias que quando criança pareciam-me eternos! Tão perenes são os anos que se perdem nas lembranças de quem os viveu sorrindo". (KOLODY, 1999, p. 29)

É possível dizer que o historiador e o literato deixam expressos em suas obras a própria visão de tempo. Tanto um quanto outro tomam o tempo para além de um dispositivo capaz de datar os acontecimentos em sua sucessão e dimensão ao perceber as permanências e as mudanças ocorridas no indivíduo e na sociedade onde está inserido. "Debruçados sobre a vida, indagamos seus mistérios e raramente alcançamos suas respostas cifradas. Não é o tempo que voa. Sou eu que vou devagar! E não mudo neste mundo que tudo muda, por mais que meu corpo me informe o contrário!”. (KOLODY, 1999, p. 29). Contudo, para a literatura, sobremaneira para a poesia, o tempo se elasticisa, torna-se menos contumaz, tornando longevo seu enunciado. Parece que o tempo para a Literatura, ao contrário da História, é um de seus fieis aliados.

Entretanto, se o homem está inscrito no tempo e no espaço onde se desenrolam os fatos, interessa ao historiador narrá-los cercado por um método e teorias que respondam suas interrogações. É preciso pontuar que a escolha de métodos e de teorias proporciona uma determinada visão de mundo e que leva a posicionamentos no próprio tempo. Para a historiografia, métodos que um dia foram válidos no estudo de um acontecimento, talvez hoje não o sejam. O tempo também dita regras que logrem o aceite ou a rejeição de um trabalho acadêmico. Se o historiador constrói narrativa privilegiando uma teoria, não estará imune à influencia das emoções, o que se revela na forma como interpreta, deduz e analisa os fatos. E a narrativa historiográfica tem prazo de validade. Não é difícil encontrar um historiador que não queira arrumar, mexer, refazer, cortar, complementar, revisar seus escritos, mesmo aqueles já defendidos em uma banca de mestrado ou doutorado. Se o historiador lida com temporalidades distintas ao narrar o passado, o tempo apresenta-se como fio condutor na busca de novos conhecimentos. Os versos em um poema, por outro lado, escapam do tempo e se rejuvenescem a cada leitura, ganhando outras vidas e outros rostos, moldados pela ressuscitante hermenêutica.

Tal pressuposto permite compreender que frases de natureza inspiradora, amalgamadas às vivências pessoais, dão-nos pistas para compreendê-las com outro viés, estando atendo às peculiaridades do pensamento, ao invés de ficarmos absortos e fascinados 
pela poesia em si. Parece ser necessário ultrapassar e dar um passo a mais para além dos limites da emoção.

A luz da lamparina dançava, frente ao ícone da Santíssima Trindade. Paciente, a avó ensinava a prostrar-se em reverência, persignar-se com três dedos e rezar em língua eslava. De mãos postas, a menina fielmente repetia palavras que ela ignorava, mas Deus entendia. (KOLODY, 1983, p. 19)

O escrito literário de Helena Kolody abre para o pesquisador novos caminhos de acesso ao entendimento de experiências religiosas e culturais, o que acabou por estabelecer proximidade e um provável parentesco entre essas áreas do saber. É esta proximidade e familiaridade que permitem existir um fluxo de informações mais freqüente, com ressonâncias significativas para ambos os modos de experienciar a realidade do outro. A escolha de palavras que formulem o pensamento literário de matiz poética e a construção de narrativa historiográfica não são aleatórias: a intenção dá o rumo do pensamento e do raciocínio. As subjetividades e a objetividade do pensamento literário e historiográfico são passíveis de investigação quando cercados pelo método de interpretação.

Os versos acima nos permitem também perguntar o lugar dos temas religiosos na Historiografia. Observa-se que no campo de estudos sobre as religiosidades tornou-se crucial entender que a diversidade de crenças existe e que tem vários sentidos e definições para poder melhor reler o pretérito. O conceito 'religião' no campo da História teve que ser compreendido com mais largueza, soltando as amarras que o unia à concepção monoteísta judaico-cristã, substituindo-o por uma definição polissêmica que "abrangesse também todo e qualquer sistema de crenças e práticas relativas ao sagrado" (SILVA; KARNAL, 2002, p.1314), sem que houvesse qualquer tipo de desqualificação ou supervalorização desta ou daquela. Assim, ampliam-se as possibilidades de se compreender os fenômenos religiosos a partir de conceitos revistos. As inúmeras pesquisas, fontes, Grupos de Trabalhos, Simpósios Temáticos têm mostrado justamente que novas expressões de fé informam (e muito!) sobre a cultura, sobre sistematização de crenças e que religião e religiosidades não significam necessariamente teologia, mas sistemas complexos de saber e de poder que se querem divinos, e que se revelam através de uma linguagem própria. De igual modo, também na literatura pode-se atentar como pessoas e grupos experienciaram crenças e manifestaram práticas religiosas poliformes. 
Por constatar que a religião imbrica-se às questões que se espraiam para além dos limites das instituições, a Historiografia e a Literatura verificam que o sagrado deixou os altares e o púlpito para ser objeto de investigação não só das ciências da religião, mas de outras áreas do conhecimento. Estas múltiplas formas de olhar, no entanto, trazem à baila a emergência de se buscar um lugar epistemológico e semântico próprios dentro do saber científico, evitando-se assim apropriações indevidas. No entanto, pontua-se que reivindicar alguns cuidados na pesquisa historiográfica sobre saberes da religião e das religiosidades não significa chancelar categorizações ou engavetar conhecimentos aprisionando-os em compartimentos fechados. Até porque a mobilidade das informações auxilia pensar amplamente o objeto em diversas perspectivas.

Sob um novo olhar, portanto, a emergência da religião e das religiosidades na historiografia contemporânea e na literatura sublinha que às ciências humanas interessa compreender o homem em muitas dimensões, inclusive a mística. O homem deixa de ser analisado somente pelo crivo da razão, percebido também em suas subjetividades, o que abre ao pesquisador novas formas de abordar suas experiências. Interessa, assim, ao historiador e ao literato não somente a religião instituída, mas também as práticas religiosas, anteriormente vistas como marginais, iletradas e populares, desvinculadas de qualquer corpo jurídico. Em alguns casos, de relegadas às puras superstições e misticismos, passam a ser objeto de análise e de interesse acadêmico à medida que se revelam cheias de sentidos e significados, próprios para a percepção do mundo no qual homens e mulheres também se relacionam com o absoluto, com o transcendente ou com realidades metafísicas, através de práticas recorrentes de cunho piedoso, não institucionalizadas. A investigação destas práticas revelou a existência de modos diferenciados do exercício da religiosidade que, longe de ser lacunar, parcial ou aproximado, se interrelacionam com outros saberes. Desmoronaram-se, portanto, as certezas, a pretensão de que só é aceitável e assimilável a fé mediada por sistemas reconhecidos e altamente organizados. Afinal, o homem religioso, leigo ou consagrado, pode tirar das coisas sagradas sentidos novos graças à hermenêutica que o faz intérprete dos fatos que o transportam para um mundo espiritual (REHFELD, 1988, p.55). Peter Berger (1985, p.107) observava nisto uma forma de alienação: o homem que nega sua realidade para buscar um mundo perfeito.

As sutilezas dos versos traçados pela poetisa Helena Kolody ao descrever o passado imbricado às coisas de sua etnia não só ressaltaram a primazia do vivido como lhe 
emprestaram o refinamento de expor o acontecido com elegância e emoção, talvez porque ela não se atreveu a esquivar-se dos detalhes que explicam tão bem a vida humana. A história e a literatura, neste caso, se aliaram para narrar o passado livre do pedantismo e dos excessos, trazendo a tona apenas o necessário. Se nos detalhes moram as chaves do cotidiano, compreendê-los nos desdobramentos do dia a dia significa compartir os traços de subjetividade que cunham a maneira de se sentir no mundo, não apenas em sua imediatez, mas como são eternizadas pela escrita.

Seja na verve de uma escrita poética ou na narrativa historiográfica os autores deixam um pouco de si, ora explícita ora metaforicamente, denunciando estilos próprios. Enredadas pelas especificidades de cada autor, tanto a Poesia quanto a História desfilam releituras de um passado de quem o observa, o analisa ou apenas sobre ele recria, guiado pela fulgurância de cada individualidade. Formulando textos que dizem sobre um determinado mundo, poetas e historiadores ao mesmo tempo em que demonstram a universalidade das palavras, revelam a face individual dos vocábulos ou pensamentos. Conduzidos pela experiência pessoal de mundo, cada autor traz à luz do entendimento o seu real e o torna acessível a outros, traduzido em linhas, em verso ou em prosa, validado pelas grades do tempo cronológico ou por aquele que não encontra nunca o seu ocaso.

Poesia e História falam do real, de verdades comprováveis, mas também do mítico, da utopia, de quimera, de desejos e de imaginário que também instituem saberes. A História observa saberes descritos na poesia como construções e dogmas que podem explicar atitudes e mentalidades. O mítico, a utopia, os desejos e o imaginário então se objetivam nos enredos da narrativa, sedimentados pela relação que têm com uma realidade simbólica e por isso observada por categorias de análise diferenciadas. Dois mundos que se interpolam, pespegados pelo amálgama da graça e da vivacidade em escrever, discorrem de diferentes modos um mesmo fato, permitindo compreendê-lo a partir dos próprios argumentos e sentidos. Haverá sempre quem ponha à prova ou conteste a necessidade de tais encontros, privilegiando seus descompassos. Contudo, em contraponto, haverá quem veja nisto recíprocos esteios referenciais que auxiliam compreender com maior margem as narrativas em seus contextos de criação e interpretação. 


\section{Referências Bibliográficas}

ARISTÓTELES. Poética. Lisboa: Imprensa Nacional Casa da Moeda, 1986.

BERGER, Peter. O Dossel sagrado: elementos para uma Teoria sociológica da religião. São Paulo: Editora Paulus, 1985.

HOBSBAWN, Eric \& RANGER, Terence. (orgs). A invenção das tradições. Rio de Janeiro: Paz e Terra, 1984.

KOLODY, Helena. Lição. In: Poesias escolhidas. Curitiba: Sociedade dos Amigos da Cultura Ucraniana, 1983.

KOLODY, Helena. Viagem no espelho. Curitiba: Editora da UFPR, 1999.

KOLODY, Helena. Creio. In: Paisagem Interior. Curitiba. Edição da Autora, 1941.

ORLANDI, Eni. P. Análise de Discurso: Princípios e Procedimentos. Campinas, SP: Pontes, 2009.

PESAVENTO, Sandra Jatahy. História \& História Cultural. Belo Horizonte: Autêntica, 2005.

REHFELD, Walter. Tempo e religião: a experiência do homem bíblico. São Paulo: Perspectiva/ EdUSP, 1988.

SILVA, Eliane Moura; KARNAL, Leandro. O Ensino Religioso na Escola Pública do Estado de São Paulo. Campinas: UNICAMP, 2002.

SILVA, Rogério Forastieri. História da historiografia. Bauru: Edusc, 2001. 